\title{
Cooperação Cooperativa: o Ser, o Fazer e o Devir
}

\author{
Cooperative Cooperation: Being, Doing, and Becoming
}

\section{RESUMO}

Contexto: a consolidação de um sistema econômico baseado na competição não eliminou a importância da cooperação para a vida em sociedade, nem impediu que organizações cooperativas continuassem emergindo, mesmo em um ambiente hostil. Por que continuam emergindo? Quais as suas possibilidades? O que acontece quando se desenvolvem? Objetivo: compreender, em termos teóricos, o fenômeno da cooperação, especialmente aquela que inspira organizações cooperativas. Metodologia: a pesquisa empreendeu uma concepção sistêmica e complexa do fenômeno da cooperação e do seu objeto de estudo, desenvolvendo uma discussão qualitativa, interpretativa e reflexiva em três eixos: o ser, o fazer e o devir. Resultados: cooperativas, como organizações humanas, passam por um processo evolutivo, sofrendo os problemas próprios da administração e manutenção da democracia. Para enfrentar o processo degenerativo é preciso repensar a gestão cooperativa com base em teorias sistêmicas e autorreforçantes da identidade cooperativa. Conclusão: a cooperação é fundamental para a vida em sociedade, o que explica o fato de cooperativas continuarem emergindo. Ao contrário do que se disseminou, não somos apenas competitivos, somos também cooperativos e nosso conhecimento precisa ser urgentemente reconstruído.

Palavras-chave: cooperação; cooperativas; desenvolvimento; organizações; sistemas.

Classificação JEL: C71, A13, F63.
1 Universidade Federal Rural do Rio de Janeiro, Departamento de Administração e Turismo, Nova Iguaçu, RJ, Brasil.

Como citar: Webering, S. I. (2020). Cooperative cooperation: Being, doing, and becoming. Revista de Administração Contemporânea, 24(6), 567-581. https://doi.org/10.1590/1982-7849rac2020190332

\section{ABSTRACT}

Context: the consolidation of an economic system based on competition has not eliminated the importance of cooperation for life in society, or the continuing emergence of cooperative organizations, even in a hostile environment. Why do they continue to emerge? What are their possibilities? What happens when they are developed? Objective: to comprehend, in theoretical terms and on the basis of existing research, the cooperation phenomenon, especially that which inspires cooperative organizations. Methodology: the research employed a systemic and complex conception of the cooperation phenomenon and of its object of study, developing a qualitative, interpretative, and reflexive discussion according to three themes: being, doing, and becoming. Results: Cooperatives, as human organizations, go through an evolutionary process, suffering the inherent problems of administration and maintenance of democracy. To face the degenerative process, it is necessary to rethink cooperative management based on systemic theories and self-reinforcing cooperative identity. Conclusion: cooperation is fundamental for life in society, which explains the fact that cooperatives continue to emerge even in the midst of a hostile environment. Contrary to what has been disseminated, we are not only competitive, we are also cooperative and our knowledge needs to be urgently reconstructed.

Keywords: cooperation; cooperative; development; organizations; systems.

Editor-chefe: Wesley Mendes-Da-Silva (Fundação Getulio Vargas, EAESP, Brasil) Celso Alexandre Alvear (Universidade Federal do Rio de Janeiro, NIDES, Brasil) Paulo Glício da Rocha (Universidade Federal de Pernambuco, DECON, Brasil) 15

Recebido em: 04/10/2019 Última versão recebida em: $27 / 04 / 2020$ Aceite em: 28/04/2020

\# de revisores convidados até a decisão:

\begin{tabular}{|c|c|c|c|c|c|c|c|c|c|}
\hline & 1 & 2 & 3 & 4 & 5 & 6 & 7 & 8 & 9 \\
\hline $1^{a}$ rodada & (x) & (x) & 9 & 8 & (x) & (x) & & & \\
\hline $2^{a}$ rodada & $\stackrel{8}{6}$ & & & & & & & & \\
\hline
\end{tabular}




\section{INTRODUÇÃO}

A consolidação de um sistema econômico baseado na competição e a ideia dominante nas ciências de que o homem reina sobre um mundo de objetos, detentor de verdades (Morin, 2007), que se autoexclui nas suas relações e responsabilidades para com os outros e a natureza (Maturana \& Varela, 1997), são uma conjugação violenta, porque predatória e insustentável. Já não devemos falar apenas em termos de crises econômicas, existe uma crise latente que é estrutural, econômica, política e sobre os vínculos humanos. Ainda assim, a cooperação sempre esteve presente, mesmo em meio ao ambiente hostil que se configurou, desde as manifestações espontâneas de altruísmo e ajuda mútua, ao uso da cooperação para realizar ações conjuntas, em prol ou não de objetivos comuns, como forma de resistência no sentido da autorrealização humana.

Este artigo é resultado de uma pesquisa que procurou compreender em termos teóricos e com base em pesquisas existentes o fenômeno da cooperação, especialmente aquela que inspira a organização cooperativa, com o objetivo de desenvolver uma concepção teórica atualizada sobre este tema. Por que continuam emergindo? Quais as suas possibilidades? O que acontece quando se desenvolvem?

Sabendo que existem epistemologias de correntes distintas e as questões relacionadas a um objeto que, embora seja um tipo de organização, está fora do foco de interesse nos estudos organizacionais tanto na Administração quanto nas Engenharias, como em outras áreas das ciências como a Economia e Ciências Sociais, a pesquisa exigiu um olhar epistemológico novo, que compreendesse a necessidade do rompimento entre as barreiras disciplinares, tendo como referencial a autonomia do pesquisador e, neste caso, também a do objeto que será estudado. Tais características se encontram nos desdobramentos mais recentes do pensamento sistêmico, que se caracterizam pela (re) aproximação entre ciência e filosofia, entre natureza e cultura, entre objeto e sujeito.

De acordo com Le Moigne (1996), um projeto sistêmico exige novas perspectivas. A primeira delas implica o reconhecimento de uma teoria de modelização que pressupõe a pluralidade dos modelos concebíveis de um mesmo fenômeno e dos métodos de modelização. A liberdade está no cerne da cognição, o conhecimento é arquitetado, não estamos reduzidos às receitas dos métodos hipotético-dedutivos, mas dispomos de um campo aberto de métodos axiomático-indutivos. A segunda perspectiva está relacionada ao paradigma da complexidade, que reconhece e aceita a complexidade do fenômeno observado. Terceira perspectiva: tudo é organização. A modelização sistêmica tem a capacidade de respeitar a "dialética constitutiva de toda a complexidade: transformarse funcionando e funcionar transformando-se, mantendo a sua identidade" (Le Moigne, 1996, p. 28). Quarta perspectiva: sistema é sistema, não é conjunto. Para superar a análise conjuntista é preciso passar da pergunta 'do que é feito?' à pergunta 'o que é que faz?'. Isto permite que se supere a modelização analítico-orgânica e que passemos a uma modelização sistemo-funcional (Le Moigne, 1996, p. 31). Quinta perspectiva: modelizar é decidir, o modelizador é dotado de liberdade criadora, que explicita ou verifica a priori os axiomas sobre os quais vai apoiar progressivamente suas inferências.

Este trabalho é resultado de uma concepção sistêmica de pesquisa, pois reconhece o seu objeto, a cooperativa, como um sistema complexo e, para responder às questões a que se propôs, foi desenvolvida nessas perspectivas. Além disso, reconhecer o mundo em transformação, e como a ciência e a construção do conhecimento transformam se transformando; tal empreendimento de modelização exige novos preceitos metodológicos (Le Moigne, 1996), explicados a seguir.

1. O preceito de pertinência afirma que o objeto é definido pelas intenções (declaradas ou não) do modelizador, por sua capacidade de desenvolver relações associadas a algumas finalidades perceptíveis e explicáveis. Isto envolve aceitar que a percepção do modelizador e o próprio objeto podem mudar.

2. O preceito de globalismo considera que o objeto a ser descoberto está inserido e ativo em um todo maior; compreender este ambiente é condição para o conhecimento do objeto.

3. O preceito teleológico interpreta o objeto pelo seu comportamento, sem procurar explicá-lo com base em alguma lei de eventual estrutura ou causalidade, procurando considerar fins, meios e suas relações (Le Moigne, 1996, p. 56).

4. Opreceito deagregatividade: toda representação é deliberadamente partidária. Busca-se por meio de alguma orientação selecionar os agregados pertinentes, reconhecendo que a objetividade do recenseamento exaustivo é irreal. Aceita-se a interpretação em termos relativos e contingentes (Le Moigne, 1996). 
Para realizar esses preceitos, além da descrição formal do que é o fenômeno ou um objeto (ao que se restringiu por muito tempo a ciência), é preciso acrescentar o que acontece quando em contato com o seu ambiente. Isto se chama a definição experimental ou praxiológica do objeto. A ênfase não está na composição, mas no comportamento. Além da essência e da experiência é preciso conhecer o objeto na sua história (hereditariedade) e no seu devir. Assim, o ser, o fazer e o devir representam uma triangulação e abertura para a representação e o conhecimento do objeto, sendo cada concepção única (Le Moigne, 1996, p. 79). Portanto, para as questões que a pesquisa se propôs a responder, pela complexidade do seu objeto (a cooperativa, que envolve um fenômeno, a cooperação), encontramos na triangulação proposta por Le Moigne (1996) um método e uma estratégia de pesquisa.

A discussão é qualitativa, interpretativa e reflexiva, com base essencialmente na interpretação de conceitos e implicações teóricas. Primeiramente é desenvolvida uma revisão histórica do fenômeno da cooperação e do cooperativismo (o ser); em seguida, são revisadas teorias resultantes de pesquisas empíricas para encontrar referências sobre o comportamento cooperativo (o fazer); por último, foram buscados alguns agregados teóricos pertinentes para a compreensão do fenômeno da cooperação, com base na teoria dos jogos, da ação coletiva e da filosofia analítica (o devir). Com isso, nos deslocamos entre paradigmas de sistemas filosóficos mais amplos (que envolvem ontologias, epistemologias e metodologias) e perspectivas não tão desenvolvidas (embora essa associação seja um exercício difícil), sobrepostas e até concorrentes, de forma reflexiva por meio de representações interligadas, desenvolvendo uma estrutura interpretativa (Denzin \& Lincoln, 2006).

Este trabalho constitui uma base para a compreensão do fenômeno da cooperação, bem como estudos sobre o desenvolvimento das cooperativas como organizações democráticas, que em um ambiente competitivo e de economia globalizada sofrem fortes pressões internas e externas, o que pode desencadear um isomorfismo no sentido de se tornarem cada vez mais parecidas com as empresas tradicionais, podendo até mesmo se degenerarem, ou resistirem adotando estratégias no sentido autorreforçante da sua identidade. É visto que, embora a ênfase tenha sido dada ao comportamento competitivo, a cooperação é o fundamento para a vida em sociedade (Bowles \& Gintis, 2011; Candau, 2018; Kropotkin, 1902) e de qualquer organização, o que explica o fato de cooperativas continuarem emergindo mesmo em meio ao ambiente hostil.

\section{COOPERAÇÃO: $O$ SER}

\section{Definição}

A cooperação possui sentidos de ação e movimento (Jesus \& Tiriba, 2003). Ação no sentido de empenho, compromisso, ainda que não seja formalizado, de empreender algo, produzindo com outras pessoas. Neste sentido se opõe ao individual, é tomar parte em um empreendimento coletivo que depende da ação de cada um. Cooperação remete também a movimento no sentido de evolução da própria história da humanidade, que se baseou na vida em coletividades e possibilitou a sobrevivência também de outras espécies (Gambetta, 1996). Complementando esse sentido de movimento, é importante a observação sobre como o coletivismo de base cooperativa foi sendo gradualmente suprimido na modernidade ocidental por diversas revoluções: a econômica, quando os indivíduos passaram a ter uma vida econômica independente da economia familiar; a revolução intelectual, referente à (re)descoberta do uso da razão; a revolução espiritual, pela liberdade do pensamento; a revolução agrícola, em que os camponeses deixaram a organização coletiva e a forma feudal; a revolução política, conquista dos direitos fundamentais; e, finalmente, a revolução industrial (Lasserre, 1972).

Ao longo desse desenvolvimento a cooperação ganhou novo significado ou forma histórica peculiar do processo de produção capitalista, transformando-se em força produtiva do capital, geradora de mais-valia através do trabalho simultâneo dos trabalhadores nos locais de trabalho (Marx, 2002), mecanismo que vem se aperfeiçoando desde o início do século passado com os desdobramentos das ciências da gestão.

Embora esse processo tenha contribuído com o desenvolvimento de uma sociedade individualista, em que se tentou suprimir as formas de organização coletiva, a cooperação continua existindo, preenchendo espaços não ocupados pelas estruturas formais e mesmo dentro delas. Por isso, existe hoje um amplo e promissor campo de estudos sobre cooperação (Bear \& Rand, 2016; Bowles \& Gintis, 2011; Candau, 2018; Grossmann; Brienza, \& Bobocel, 2017). Desde a perspectiva da pesquisa científica, o estudo da cooperação é difícil devido à sua sofisticação conceitual e da dificuldade de analisá-la, pois envolve a monitoração de diferentes agentes em interação em ambientes complexos (Gambetta, 1996). Além disso, a cooperação normalmente está vinculada a outras densas discussões teóricas como confiança, moral, reconhecimento, cultura, altruísmo e solidariedade. Recursos que não podem ser fabricados, comprados ou mensurados. Embora o mercado venha se interessando, constituem um capital que não pode 
ser controlado e se esconde na sociabilidade humana (Bauman, 2004).

Uma das principais referências para o estudo da cooperação é Piotr Kropotkin (1842-1921), de modo especial sua obra Mutual aid, em que desenvolveu uma análise generosa da evolução humana, sendo importante referência para compreender as origens das práticas de cooperação, contrastando com o conceito de seleção natural darwinista (Bowles \& Gintis, 2011). Baseado nas observações feitas durante suas viagens, Kropotkin (1902) percebeu a esmagadora importância na natureza daquilo que Darwin descreveu como 'the natural checks to over-multiplication' em comparação à luta de indivíduos de uma mesma espécie pelos meios de sobrevivência, presente em determinadas circunstâncias, porém que nunca supera a primeira. $\mathrm{O}$ fator de maior importância para a manutenção e preservação das espécies e sua mais profunda evolução seria a ajuda e o suporte mútuos entre os indivíduos de uma mesma espécie. Kropotkin (1902) observou um período de evolução comprometedor justamente em períodos de calamidade/escassez de alimentos, quando indivíduos fisicamente debilitados, em um esforço para preservar a vida, desenvolvem competição. $\mathrm{O}$ autor critica o pensamento de darwinistas (não Darwin, propriamente) e sociólogos de que o homem, por possuir uma inteligência superior, pode mitigar o esforço e competição pela vida entre os indivíduos de sua própria espécie. No entanto, ao mesmo tempo, consideram a competição pelos meios de sobrevivência como uma lei da natureza (Kropotkin, 1902).

As instituições de ajuda mútua são grupamentos humanos existentes desde os períodos mais remotos da espécie humana e responsáveis pelo seu desenvolvimento. A imensa influência que essas instituições exerceram sobre a espécie humana levou o autor a pesquisar outros períodos, incluindo as instituições de ajuda mútua do seu tempo, quando ocorreu a expansão dos sindicatos e cooperativas na sociedade industrializada, também os diversos tipos de associações como clubes, grupos de estudos e ensino (Kropotkin, 1902).

Naquele contexto de consolidação da organização do trabalho e produção capitalistas, o diferencial da cooperação residia justamente na experimentação de diferentes formas de organização capazes de emancipar os trabalhadores do trabalho assalariado, uma vez que eles se organizavam em associações igualitárias e livres (o que continua sendo o seu diferencial). Nesses termos, cooperação representa a autogestão através: da participação na gestão, do interesse coletivo na produção, da eleição direta dos órgãos de gestão, da igualdade entre os votantes, da definição de objetivos coletivos para o conjunto da empresa, do rodízio de responsabilidades, apenas para citar alguns (Arvon, 1985).
Portanto, a cooperação em empreendimentos coletivos é diferente daquela descrita por Marx (2002) no processo de produção capitalista, em que os trabalhadores desenvolvem atividades conjuntas, mas sem vínculos entre eles, sem a posse dos meios de produção, tendo como elo apenas a figura do capitalista. Aqui a vinculação ocorre entre os trabalhadores, que formam de maneira voluntária e consciente associações de trabalho, porque entendem que sua força está na organização coletiva. Essa constitui uma modalidade específica de organização do trabalho em cooperação, capaz de gerar uma sociabilidade diferenciada.

\section{Histórico do cooperativismo}

A história do cooperativismo normalmente está vinculada à fundação em 1844 da Cooperativa de Rochdale no Reino Unido, onde se originariam os princípios cooperativistas. Porém, a experiência cooperativa é anterior a esta, a Robert Owen que a influenciou ou a Fourier na França, considerados utopistas que inspiraram o movimento cooperativo. As origens das cooperativas rurais e agrícolas encontram-se, em parte, relacionadas às experiências coletivistas de ajuda mútua no campo e, em parte, às condições da agricultura moderna, tendo se desenvolvido desde que a economia rural passou a estar relacionada ao mercado - seja pela necessidade de crédito, da aquisição de adubos, sementes, entre outros, seja pela necessidade de comercialização da produção. Já as cooperativas urbanas nasceram em meio ao desenvolvimento do capitalismo industrial, juntamente com o movimento operário, através de experiências que suprimissem o trabalho assalariado, expressas pelas cooperativas de produção. Também como desenvolvimento de mecanismos que liberassem a maneira de dispor de seus salários e poder de compra, por meio da ação cooperativa de consumo e habitação, também de modo a inibir os truck systems (sistemas em que o empregado se endividava com o empregador por meio da compra de mercadorias) (Fauquet, 1980).

No contexto das últimas décadas do século XIX e as primeiras do século XX ocorreram divergências entre os que pensavam as práticas de cooperação que inspiraram o cooperativismo, o ideário anarquista que previa um projeto autogestionário de sociedade e a transformação social via revolução e tomada do poder, o que gerou diferentes perspectivas quanto aos desdobramentos possíveis das experiências de organização coletiva e democrática do trabalho e até mesmo o afastamento de marxistas e movimento operário do cooperativismo, considerado por alguns uma experiência burguesa. Esses elementos contribuíram com que gradualmente a forma institucional cooperativa fosse assimilada quase que exclusivamente por um movimento cooperativo. Uma 
corrente começou a pensar na existência de um setor específico da economia de mercado em que estariam inseridas as cooperativas (Fauquet, 1980), contribuindo com o estudo do cooperativismo especificamente, seu papel, características e desdobramentos.

No início do século XX, alguns cooperadores ainda pensavam que, em um livre mercado, o desenvolvimento indefinido de instituições cooperativistas seria capaz de absorver, pouco a pouco, a livre concorrência. Fauquet defendeu - então, década de 1930 - a ideia de que o próprio capitalismo havia passado por transformações. A livre concorrência estava comprometida pelo poder de trustes e cartéis, as grandes corporações e empresas capitalistas estavam cooperando. $\mathrm{O}$ movimento cooperativo deveria se ajustar às mudanças: não poderia mais esperar o crescimento indefinido em um ambiente de liberdade econômica, para se afirmar tornava-se necessário refletir sobre o seu conteúdo e características (Fauquet, 1980).

A preponderância que as formas capitalistas haviam adquirido talvez fosse mais pela influência exercida pela imprensa, poderes públicos, costumes e a sociedade como um todo do que propriamente sua intervenção em fatos puramente econômicos. Apesar da constatação daquela nova realidade de predomínio das organizações capitalistas, constatava-se que elas não haviam feito desaparecer antigas formas não capitalistas, nem impediam que novas instituições continuassem surgindo (Fauquet, 1980).

A consolidação de um movimento cooperativo internacional e a concepção de um setor cooperativo contribuíram com que o termo Economia Social perdesse força na primeira metade do século XX. Isso ocorreu porque o termo Economia Social surgiu na Europa no início do século XIX, em meio a um debate no pensamento econômico que se referia às relações entre política, economia e valores, além do papel do trabalho cooperativo e da associação entre trabalhadores na economia. O termo seria retomado nas décadas de 1970 e 1980 devido à crise econômica eà solidariedade entre os movimentos socioeconômicos, como a aproximação entre associações, cooperativas e sociedades de socorro mútuo em alguns países europeus, nas discussões para uma economia plural (Chaves, 1999). Um movimento semelhante ocorreu no final dos anos 90 nos países da América Latina e da África, aparecendo então como Economia Solidária ou Economia Social e Solidária. Portanto, apesar da predominância das organizações capitalistas, as antigas formas de organização baseadas na cooperação não desapareceram.

Além da transformação do contexto em que estavam inseridas as cooperativas, já no início do século $\mathrm{XX}$, estudos apontavam as dificuldades enfrentadas por essas empresas quanto à manutenção da sua democracia (Meister, 1969), seja pelas dificuldades próprias de uma gestão democrática, participativa, que busca o consenso e realização plena dos seus membros, seja por dificuldades relacionadas ao crescimento e ao desenvolvimento de populações diferenciadas no interior das cooperativas - população de sócios, administradores eleitos, gerentes e empregados assalariados (Desroche, 2006) -, bem como a criação de redes ou grupos cooperativos que podem tender, ou não, no sentido de uma gestão compartilhada democratizante.

Para Desroche (2006), a economia cooperativa estava associada a uma ética de contestação presente no cooperativismo de influência cristã ou nas formas variadas como foi interpretado pelo socialismo. O cooperativismo tratado em termos de princípios ou postulados corre o risco de se distanciar da moral que o originou, tornando-se uma doutrina vaga, e suscetível de ser explorado de maneira reformista por meio de coletivos dentro do regime capitalista de livre empresa. Mesmo dentro de experimentos socialistas reais, tornou-se burocrático através de um Estado centralizado e planejado que negligenciava a cooperação. Por essas razões, Desroche compreendeu que era preciso trabalhar uma ética cooperativa, capaz de contemplar o pluralismo do cooperativismo enquanto movimento internacional. Com base em suas pesquisas sugeriu que a ética cooperativa envolve os elementos: (a) criatividade, relacionada ao prazer de criar o grupo, a empresa, em desenvolver relações, movimentos, etc.; (b) solidariedade, manifesta nos limites dos direitos e interesses do capital, com ênfase nos resultados sociais; o cooperador abre mão dos seus interesses imediatos na expectativa de encontrar um regime econômico capaz de gerar um nível de vida superior, melhor para ele e o grupo em que está inserido; (c) ecumenicidade, que reconhece um ponto de coincidência entre os interesses na cooperação e solidariedade, permitindo uma prática comum, que pode abrigar diferentes referências; o conjunto é coerente com as ideologias de cada uma das partes; (d) uma ética de responsabilidade, contrapondo-se e equilibrando-se com a ética de convicção (que neste caso se relaciona com os outros elementos citados), com o sentido complementário entre ambas proposto por Weber (2009), o que pode ser a fragilidade do cooperativismo, mas também o seu vigor, sua capacidade de combinar o valor humano ao peso das responsabilidades (Desroche, 2006).

Ao revisar as origens e a discussão sobre as práticas de cooperação e o cooperativismo, nos deparamos também com as transformações ocorridas ao longo desse período e como a discussão da cooperação não teve repercussão importante tanto no pensamento e experiências socialistas quanto no mundo capitalista. No entanto, mesmo em meio a esse ambiente hostil, continuam emergindo, como base para a sociabilidade humana ou como forma de resistência. 


\section{TENSÕES NO DESENVOLVIMENTO DE COOPERATIVAS: $O$ FAZER}

A evolução cooperativa, quando acontece, gera um grande desafio: evitar a perda da participação/ democracia e degeneração - desaparecimento da cooperativa, sua absorção por outro grupo ou transformação jurídica (Bretos \& Errasti, 2016, 2018; Chaves \& Sajardo, 2004; Cheney, Cruz, Peredo, \& Nazareno, 2014; Errasti, 2013; Martínez, 2005; Spear, 2004).

A tese da degeneração basicamente estabelece que as cooperativas tenderão inevitavelmente a adotar o mesmo modelo organizacional das empresas tradicionais para sobreviver, desenvolvendo gradualmente uma elite dirigente que desestimula a democracia. Devido à necessidade de incrementar a eficiência e em função disso o crescimento, as cooperativas precisam desenvolver novas estruturas e divisão do trabalho. Os trabalhadores não sócios podem se tornar numerosos e os objetivos muito semelhantes aos das empresas tradicionais (Cornforth, 1995). Essa tese tem origem no marxismo e na crítica socialista de que operando em um sistema capitalista as cooperativas são experiências limitadas e acabam refletindo esse sistema. Também em outras teorias e estudos, como a teoria das elites (Michels, 1969).

Por sua vez, a tese da degeneração também sofre críticas. A tese de Michels (1969), por exemplo, de que ao assumir a democracia direta como modelo padrão que contrapõe outras formas de organização, julga-se que qualquer forma de representação ou delegação é um sinal de oligarquia. Essa ideia sofre a crítica de que a partir de determinado tamanho qualquer organização necessita de algum tipo de delegação ou forma de representação, portanto seria realmente correto afirmar que toda grande organização é uma oligarquia? Em uma segunda crítica, afirma-se que os líderes, devido à posição que ocupam, passam necessariamente a pertencer a um mundo diferente dos liderados, perdendo contato com os membros e seus interesses. Na realidade, isso pode não acontecer obrigatoriamente, sendo importante lembrar que as cooperativas são menores do que sindicatos e partidos políticos, foco da análise de Michels (1969). Também a evolução cooperativa em que se perde gradualmente a participação, descrita por Meister (1969), seria demasiadamente pessimista (Cornforth, 1995).

Desde a perspectiva teórica, resumidamente existem duas críticas principais à tese da degeneração: primeiro, a de que é extremamente determinística, negando a possibilidade de que os que cooperam têm alguma autonomia em relação à sua forma de organização; segundo, desenvolve uma visão idealizada da democracia que seria inviável, exceto em organizações pequenas. Além disso, cada cooperativa tem um contexto econômico, tecnológico, social e político específico que não deve ser ignorado (Cornforth, 1995).

Com base em argumentos como esses, desenvolveu-se uma linha que contrapõe a tese da inevitável degeneração, defendendo/verificando que processos de regeneração também ocorrem em diferentes fases do ciclo de vida cooperativo, devido a um reconhecimento de que houve um afastamento entre a realidade e a retórica democrática (Cornforth, 1995; Bialoskorski Neto, 2004; Coque Martinez, 2005; Stryjan, 1994).

Não obstante, em sua evolução as cooperativas defrontam-se com um desafio talvez mais difícil do que as empresas tradicionais, o equilíbrio entre crescimento quantitativo e desenvolvimento qualitativo, que envolve a conservação de sua identidade. Coque Martínez (2005) realizou uma adaptação do ciclo de vida organizacional à realidade das cooperativas e o sintetiza nas seguintes fases (Coque Martínez, 2005).

Fase 1 - caracteriza-se pelo número pequeno de sócios e volume reduzido de operações, o que permite que os sistemas sejam mais informais e que haja uma aversão às práticas empresariais; desde o início são determinados os mecanismos de participação. Essa fase talvez seja a mais difícil de se superar, pela falta de experiência e recursos.

Fase 2 - verifica-se o aumento do número de sócios e necessidade de contratação de técnicos remunerados, bem como equilíbrio entre racionalização das atividades e identidade cooperativa. Vigilância do funcionamento interno frente aos desafios do crescimento, consolidação das formas de participação, preocupação com a qualificação e perfil das pessoas contratadas, com os mecanismos de inserção de novos sócios e gerentes.

Fase 3 - a participação é ameaçada pelo crescimento da burocracia e tecnocracia. Nessa fase, o grupo de sócios fundadores normalmente já foi ou está sendo completamente substituído. É preciso desenvolver ferramentas que estimulem a renovação da confiança, participação e descentralização. O crescimento interno por vias de participação chega ao seu limite, o desenvolvimento passa a ocorrer por relações externas. Experimenta-se maior risco de degeneração (Coque Martinez, 2005), mas se verificam também processos de regeneração (Cornforth, 1995).

A autogestão é permeada por contradições, por isso, ela deveria ser vista como um processo de reprodução constante. Qualquer pesquisa nessa área deve ser precedida de um exame das possíveis 
falhas e êxitos, pois a diferença fundamental entre as cooperativas e as empresas tradicionais são os tipos de problemas encontrados e as soluções para enfrentá-los (Stryjan, 1994).

Stryjan (1994) desenvolveu a perspectiva da reprodução cooperativa, oferecendo uma orientação sistêmica - trabalho, gestão e redesenho constante do projeto organizacional - para lidar com os desafios das mudanças e estabilidade organizacional, baseando-se primordialmente nos conceitos de membros e inputs gerados por eles. Através das interações, os membros constroem a organização e são formados, compartilhando visões e ações.

Ao longo do tempo, a maneira pela qual a organização responde aos inputs de seus membros determinará a composição da sua população, o que influencia o tipo de indivíduo que ela irá atrair e reter. A partir daí muitos caminhos podem ser tomados e a degeneração é apenas um deles. Além das influências ambientais (Baum, 2007; Hannan \& Freeman, 2005; Dimaggio \& Powell, 2005) às quais as cooperativas também estão suscetíveis, sua degeneração pode ser o resultado combinado da má administração dos inputs - que em determinadas circunstâncias teriam efeito corretivo - e a deterioração da população restante, bem como de novos membros (Stryjan, 1994).

Para não degenerar, cooperativas deveriam atuar em duas grandes frentes. A primeira se dá na perspectiva da reprodução de membros ativos, através de sua seleção e socialização adequada (Stryjan, 1994). Isso pode parecer estranho, pois em si é uma adaptação do princípio de livre adesão dos membros a um contexto onde um elemento importante para o cooperativismo é mais difícil de ser encontrado e realizado: a afinidade entre membros e interesse em participar. Práticas que estimulam o desenvolvimento de significados comuns e comprometimento, como processos formativos, discussão construtiva e rotatividade de tarefas, mostraram-se cruciais em casos de cooperativas que conseguiram manter a democracia interna. Isso é particularmente importante com o crescimento, quando o contato entre os membros se torna mais difícil ou formal, e na medida em que a motivação para participar é maior quando membros são capazes de desenvolver atividades variadas e importantes (Stryjan, 1994; Cornforth, 1995).

A segunda frente de atuação está relacionada à divisão do trabalho e gestão da estrutura. Esses dois aspectos estão relacionados à necessidade de incrementar a eficiência e a divisão horizontal do trabalho. Porém, uma maior especialização e diferenciação interna não necessariamente geram o desenvolvimento de uma elite ou enfraquecem a democracia. A experiência mostra casos em que se observou justamente o contrário: membros mais atentos ao que estava acontecendo, exercitando a participação e controle de informações por meio de políticas fortemente comprometidas com a rotatividade de tarefas e compartilhamento de conhecimentos, informações e tecnologias adequadas; ou, em alguns casos, por meio de equipes de apoio rotativas responsáveis por manter essa dinâmica. Porém, essas medidas apenas não garantem que se evite a formação de elites dentro do grupo, é importante que haja uma predisposição por parte daqueles que ocupam posições-chave. A partir de determinado tamanho, normalmente ao redor dos 15 ou 20 membros, o envolvimento democrático pode ser garantido através do desenvolvimento de uma estrutura democrática mais complexa que combina formas representativas e de participação direta, que reforçam uma à outra (Cornforth, 1995).

Desde uma perspectiva ambiental, Bager (1994) desenvolveu um estudo do processo de isomorfismo adaptado à realidade cooperativa, concluindo que esta sofre um isomorfismo congruente e um não congruente. $O$ primeiro exerce uma força no sentido de homogeneização em relação ao próprio modelo cooperativo por meio de legislações cooperativistas, de um quadro institucional cooperativo (instituições promotoras nacionais e internacionais, federações regionais e nacionais, em alguns casos cooperativas de crédito, organizações guarda-chuvas, etc.), da competição (que às vezes também existe) entre cooperativas e da cooperação com outras cooperativas ou organizações de mesma base social. O segundo exerce uma força no sentido de homogeneização em relação a outras formas organizacionais por meio da legislação das empresas e comércio em geral, do campo organizacional do setor em que há atuação de empresas tradicionais capitalistas de fins lucrativos, da competição com outros tipos de organizações, da cooperação com outros tipos de organizações e de empregados ou gerentes que não têm perfil cooperativo e organizações profissionais.

Portanto, estimar um equilíbrio entre essas duas formas de isomorfismo seria uma questão fundamental para o estudo do processo de transformação. O predomínio de isomorfismo não congruente estimula o processo de transformação, sendo o seu extremo a degeneração. Contudo, essa estimativa é desafiadora e exige uma análise histórica do processo de mudança. Os contextos setores, tipos de cooperativa e países - são muitos, o que ajuda a compor processos isomórficos variados. Além disso, assim como nos outros tipos de organizações, não só o isomorfismo influencia o processo de mudança, mas também as ações gerenciais (Baum, 1997) e, no caso das cooperativas, a perspectiva de reprodução interna dos membros (Stryjan, 1994). Por essas razões, a formação e 
seleção de gerentes com perfil da economia social e solidária têm se mostrado importantes (Chaves Ávila \& Sajardo, 2004; Spear, 2004; Mozas Moral, 2004).

Portanto, cooperativas precisam rever a sua performance econômica e social permanentemente para evitar a degeneração, em um ciclo de constante vigilância e aperfeiçoamento, reinventando-se a cada dia. Não existe um modelo para que dê certo. Assim como as circunstâncias mudam, novos procedimentos e estruturas precisam ser revistos pelos próprios membros, o que demanda uma capacidade de intercâmbio contínuo (Cornforth, 1995; Stryjan, 1994).

Manoa (2001) analisa a cooperativa como uma organização dual, semiaberta, que combina ao mesmo tempo dois tipos de trocas: trocas internas desenvolvidas pelo grupamento de pessoas que constituem a organização e trocas com o mercado. A existência das trocas internas é o primeiro fator que deve ser considerado e conservado na dinâmica cooperativa, já que constitui uma vantagem indiscutível com relação à empresa tradicional. É o que numerosos trabalhos teóricos, de epistemologias e métodos diferentes, vêm igualmente concluindo (Manoa, 2001, p. 33).

As trocas internas são o cerne da empresa democrática, estão intrinsecamente ligadas a ela e se desenvolvem sem quaisquer custos diretos implicados, pois sua base se encontra na cooperação, principal vantagem comparativa desse tipo de organização e, ao mesmo tempo, o que torna sua sobrevivência mais difícil numa lógica concorrencial (Manoa, 2001). Paradoxalmente, é essa característica que a empresa tradicional nos dias de hoje vem tentando reproduzir, diante da necessidade de produção/serviços cada vez mais personalizados e criativos. A empresa tradicional busca desenvolver essa característica de maneira extremamente custosa, normalmente através da contratação de pessoal altamente qualificado, salários diferenciados e programas constantes de formação e incentivos, de forma a conseguir informações e competências diferenciáveis no mercado competitivo.

\section{AGREGADOS TEÓRICOS PARA O ESTUDO DAS COOPERATIVAS: $O$ DEVIR}

A teoria dos jogos é reconhecida como uma área que contribui com modelos importantes de representação para os fenômenos sociais coletivos, pois gera um aparato lógico e prático para a sua interpretação e explicação (Ullmann-Margalit, 1977). Tanto que pesquisadores dessa linha têm dado importância ao fenômeno de emergência da cooperação (Bear \& Rand, 2016; Fiani, 2006), contribuindo com estudos nas áreas de Economia, Ciências Sociais e até mesmo a Filosofia. Na Economia, a teoria dos jogos é aplicada não somente dentro de uma visão propriamente cooperativa, mas também competitiva (custos de transação, possibilidades de cooperação econômica, etc.). Em áreas como as Ciências Sociais e Filosofia, existe o interesse especial por formas de cooperação espontânea, suas condições e sua viabilidade para o aumento do bem-estar da sociedade, justamente porque é mais difícil estimular a cooperação por mecanismos externos, ainda que existam mecanismos de recompensa ou penalidades para os 'jogadores'. Esse papel é exercido na realidade pelas instâncias jurídicas, polícia, agências reguladoras, associações profissionais, sindicatos e outros. Porém, para a vida em sociedade é necessário que uma parcela considerável da população escolha cooperar espontaneamente (Fiani, 2006).

Um aporte é o estudo da emergência da cooperação em jogos repetidos, simulando situações reais em que jogadores voltam a se encontrar, desenvolvendo um processo de interação estratégica infinita, no sentido de que os jogadores não sabem quando o processo irá terminar (Fiani, 2006). O dilema dos prisioneiros vem servindo como base para diversos estudos pelo fato de representar situações comuns, desde as relações pessoais até as relações entre nações. $\mathrm{Na}$ vida real, a estratégia adotada (cooperar ou desertar) depende das circunstâncias em que se encontra cada jogador, suas características e suas expectativas individuais (Axelrod, 2010). Na Tabela 1 , encontra-se a representação do dilema dos prisioneiros.

Tabela 1. O dilema dos prisioneiros.

\begin{tabular}{|c|c|c|}
\hline & Cooperar & Desertar \\
\hline \multirow{2}{*}{ Cooperar } & $\mathrm{R}=3, \mathrm{R}=3$ & $\mathrm{~S}=0, \mathrm{~T}=5$ \\
\hline & Recompensa (R) pela mútua cooperação & Pagamento do simplório (S); tentação $(\mathrm{T})$ para desertar \\
\hline \multirow{2}{*}{ Desertar } & $\mathrm{T}=5, \mathrm{~S}=0$ & $\mathrm{P}=1, \mathrm{P}=1$ \\
\hline & Tentação (T) para desertar e pagamento do simplório (S) & Punição (P) pela deserção mútua \\
\hline
\end{tabular}

Nota. Fonte: Axelrod, R. (2010). A evolução da cooperação. (p. 8). São Paulo: Leopardo Editora. 
Uma dificuldade encontrada para a adoção da estratégia cooperar-cooperar, de resultado mais equilibrado, deve-se aos jogadores tenderem a selecionar sua estratégia ótima. Essa situação é ineficiente, porque a não cooperação por parte de um jogador enquanto o outro coopera (ou os demais cooperam) gera recompensas que superam o comportamento cooperativo somente no curto prazo. Se os jogadores voltam a se encontrar, com o histórico das jogadas, começam a reproduzir o comportamento não cooperativo, desencadeando o pior resultado. $\mathrm{O}$ oportunismo de curto prazo descrito pelo dilema dos prisioneiros tem péssimos resultados, das interações mais simples às mais complexas, em uma sociedade (Fiani, 2006).

O trabalho de Axelrod tem repercutido nos estudos sobre cooperação desde a década da publicação do trabalho The evolution of cooperation, em 1984. Baseado no dilema dos prisioneiros, Axelrold desenvolveu um torneio de computador contando com as estratégias enviadas por profissionais de diversos países - somente na segunda fase, foi simulado mais de um milhão de jogadas. A abordagem desenvolvida esteve baseada em estratégia e não em genética, utilizando-se de uma perspectiva ecológica em que estratégias eficazes vão sendo imitadas e as malsucedidas tendem a não ressurgir ao longo do tempo, não ocorrendo mutação de estratégias, mas um processo de aprendizagem, sendo possível observar a distribuição das estratégias ao longo das rodadas. As estratégias exploradoras - que não cooperam ou desertoras - estão entre as de pior desempenho porque, na medida em que o tempo passa, sua base de exploradas diminui, sendo assim insustentáveis.

A estratégia que surpreendentemente obteve maior sucesso, não necessariamente em pontuação, mas em estabilidade e resultado médio ao longo das gerações de torneios, foi a Olho Por Olho: considerada uma estratégia do tipo gentil; preventiva de problemas desnecessários; que não permite a exploração; clemente, pois é capaz de restaurar a cooperação; clara, permitindo sua fácil compreensão; e estimuladora da cooperação no longo-prazo. O sucesso desta estratégia se deve a estimular a cooperação e não a competição, pois se baseia no princípio da reciprocidade: uma atitude gentil de cooperação obtém o melhor desempenho no longo prazo, podendo alcançar estabilidade coletiva em circunstâncias em que o futuro é relevante para os jogadores, sendo requisito a durabilidade das relações e não necessariamente amizade ou afinidade. Estes aspectos estão relacionados à capacidade de previsão humana, algo bastante semelhante ao que defendeu Kropotkin (1902). Outra conclusão importante é que a estratégia de desertar também pode obter estabilidade coletiva e em qualquer circunstância, uma vez que se baseia no interesse próprio e imediato. Porém, essa estratégia não obtém melhor desempenho seja no presente, seja no futuro (Axelrod, 2010).

A cooperação pode emergir mesmo em um mundo de desertores, desde que indivíduos cooperantes tenham a oportunidade de interagir entre si, sendo capazes de se proteger dos que adotam outras estratégias. Para isto, a estratégia gentil precisa ser motivada e desenvolver estabilidade coletiva, sendo capaz até mesmo de dominar em um mundo de egoístas por meio de grupos de indivíduos que dependem da reciprocidade. Essa experiência sugere que a cooperação surja mesmo em casos em que não exista amizade ou previsão, como no caso real do viva e deixe viver nas trincheiras de guerra (Axelrod, 2010).

Reconhecer a sociedade como um sistema em que a cooperação desempenha um papel fundamental justifica a relevância do desenvolvimento de pesquisas sobre este tema. Um grande desafio é que o aprendizado por tentativa e erro é lento, portanto, deveria haver um empenho, por meio de uma melhor compreensão desse processo, em desenvolver condições propícias à evolução da cooperação e não o contrário (Axelrod, 2010).

O filósofo finlandês Raimo Tuomela, interessado por questões relacionadas à ação social, também defende que é preciso conhecer melhor os mecanismos da cooperação e as condições para que ela se desenvolva. Este autor reconhece que a teoria dos jogos é um modelo útil de representação, contudo, critica a maneira inadequada como a cooperação normalmente é tratada, seguindo a abordagem individualista e ignorando a questão social. Tuomela defende seu uso associado ao estudo dos dilemas da ação coletiva (Tuomela, 2000).

Utilizando-se da filosofia analítica, Tuomela (2000) desenvolve as possibilidades de uma cooperação mais efetiva, denominada full-blown cooperation, por meio de questionamentos filosóficos, analisando não só os tipos de cooperação possíveis, mas também em quais circunstâncias são de fato possíveis, úteis, racionais e desde que pontos de vista. Seu objetivo é oferecer uma teoria satisfatória sobre cooperação, analisando a noção de cooperação e apresentando uma taxonomia das suas subvariedades. Entre elas, uma distinção crucial: group-mode cooperation (g-cooperation) e I-mode cooperation (I-cooperation); a primeira se baseia em um comprometimento com o coletivo, a última com interesses privados. A teoria dos jogos pode resolver muitos aspectos relacionados à cooperação de tipo I-cooperation, mas para ir além é preciso realizar conexões entre os campos da Filosofia e as Ciências Sociais, como reconheceu também Axelrod (2010).

Supondo-se uma (pré)disposição para a cooperação na espécie humana (Kropotkin, 1902; 
Bowles; Gintis, 2011), é difícil prever em quais circunstâncias os indivíduos se dispõem a cooperar ou a desertar, agindo de maneira competitiva, egoísta ou mesmo agressiva. Sendo assim, é importante descobrir mais sobre a natureza da cooperação e as condições favoráveis para o seu desenvolvimento, uma vez que é condicionada também pelo contexto institucional e normativo dos grupamentos sociais e da sociedade de maneira mais ampla.

Tuomela (2000) se aproxima do estudo da cooperação por meio de uma teoria filosófica sobre a ação social, argumentando que o agir com sentido conjunto e o comprometimento coletivo são aspectos centrais para um tipo de cooperação mais sofisticada e desabrochada (full-blown cooperative action). Este tipo de cooperação surge a partir de uma g-cooperation, em que os indivíduos atuam juntos intencionalmente buscando realizar um objetivo coletivo, ao mesmo tempo que estão ou não perseguindo seus objetivos ou interesses privados.

O tipo de cooperação que aparece em jogos como o dilema dos prisioneiros é considerado um tipo de cooperação fraca, I-cooperation, e ocorre pela colaboração ou coordenação; o indivíduo coopera pelo interesse de realizar seus objetivos e interesses privados. Os dois tipos de cooperação são importantes como objeto de estudo, embora a maioria dos estudos empíricos venha dedicando-se mais à cooperação no sentido de colaboração (coaction) (Tuomela, 2000).

Pessoas são seres pensantes, que sentem e atuam de acordo com uma moral, cooperam e questionam uns aos outros, construindo e mantendo entidades sociais. Nossas ações ocorrem em um contexto social, dependem da existência de outros indivíduos, por razões sociais, e nós pensamos intuitivamente em cooperar ou não. A cooperação é analisada então como ação social, variando da mais fraca à mais forte. Idealmente, uma pessoa desenvolve uma ação pensando no seu grupo (group-attitude) se, e somente se, ele ou ela: tem (ou compartilha) essa atitude; acredita que o grupo tenha essa atitude; acredita que haja uma expectativa mútua entre os membros para que todos tenham essa atitude. Uma group attitude é uma razão social compartilhada, pela qual os agentes se guiam, constituindo a intenção da ação social em questão. Ela é social, pois precisa levar em conta as outras pessoas, enquanto participantes da cooperação. Isto cria o tipo de dependência, física ou mental, necessária para que haja cooperação, o que seria uma condição coletiva. Agir junto de maneira fortalecida requer atuar em associação com outros, de acordo com um plano de ação comum (Tuomela, 2000).

As preferências dos participantes em uma ação social podem ser totalmente cooperativas se estiverem muito correlacionadas ou o oposto. A correlação de interesses determina o tipo de cooperação: existem motivações e racionalidades que subjazem a cooperação, ou seja, são preferências ou interesses relacionados à necessidade de associação ou ação coletiva. Dependendo do caso, a cooperação pode ser também natural ou institucional e, ainda, altamente dependente da cultura. Não se trata de uma dicotomia, mas de diferentes formas e variações da cooperação, dependendo dos contextos (Tuomela, 2000).

Cooperar em uma situação definida por uma normativa pressupõe que os participantes aceitem os objetivos, as tarefas, as responsabilidades definidas. No entanto, a correspondência entre as preferências em questão será em parte determinada por normativas, pois são previamente definidas por acordo ou norma social, o que representa uma expectativa mútua em relação ao que a norma determina ou regulamenta. Um participante pode ainda cooperar em determinadas situações com boa vontade ou relutante - por exemplo, no caso de uma greve, em que por votos ela é declarada e membros que não eram a favor se vêm obrigados a participar (Tuomela, 2000).

As pessoas propensas a cooperar podem transformar essa atitude em um modo de vida, pois passam a levar em conta que é recompensador agir assim nas situações com que se deparam. Aqui, a ação e os desdobramentos associados a ela podem não estar necessariamente relacionados ao altruísmo, mas são resultado da prática, da experiência, do conhecimento construído pelo próprio indivíduo. Essa recompensa por cooperar pode ser percebida tanto pela realização dos objetivos quanto pela participação nas atividades-meio (Tuomela, 2000).

Uma ação coletiva também pode estar baseada em um forte senso de envolvimento com o coletivo, mas sem que esteja necessariamente acordada, formalizada, deliberada. Agir junto pode estar baseado em um plano compartilhado, em princípios compartilhados, confiança mútua ou com base em uma confiança razoável (plain belief) (Tuomela, 2000).

Já em grupos formalmente estruturados, normalmente existe uma ou mais pessoas responsáveis por operar decisões e ajudar a formar as intenções de cooperação, bem como contribuir com a sua realização. Nesses casos, supõe-se que o restante do grupo coopere em algum nível. Alguns membros podem contribuir com as finalidades do grupo sem que realmente estejam envolvidos com aqueles objetivos, enquanto outros aceitam esses objetivos e ações apenas tacitamente, sem intenção de colaborar. Pode-se dizer que estes dois últimos casos são variações de i-cooperation (Tuomela, 2000).

Sem dúvida, a discussão da cooperação e da realização de objetivos coletivos compartilhados se depara com discussões mais amplas da vida em 
sociedade, relacionadas a metaníveis filosóficos acerca da organização social - liberal, comunitarista, republicana, libertária, etc. Tuomela (2000) procura fugir dessas discussões e assume apenas que a sociedade é constituída por instituições sociais que geralmente, ou pelo menos na maioria dos casos, dependem de cooperação.

A discussão das condições para o desenvolvimento da cooperação remete a outro conceito importante que contribui com a manutenção das entidades sociais, sejam elas de natureza colaborativa desigual, como no caso da I-cooperation, sejam entidades mais igualitárias nos termos de uma g-cooperation: são as normas sociais, resultantes da ação e experiência humanas, não necessariamente implementadas de modo deliberado, e que influenciam a conduta dos indivíduos.

O surgimento das normas e padrões de conduta é complexo e está relacionado ao processo de racionalização das sociedades ocidentais e às transformações do trabalho e das interações humanas. Outro exemplo foi o uso abusivo da teoria da evolução darwiniana para justificar a competição e os propósitos da estrutura de classes sociais nos contextos de desigualdade. Justificativas como estas contribuíram com a assimilação de um padrão para toda a sociedade e para atender de maneira satisfatória a interesses que emergiram de forma desordenada. Normas não passam a existir em um momento determinado, nem são resultado de ações deliberadas. Elas são resultado de um complexo padrão de comportamento de grande número de pessoas ao passar do tempo (Ullmann-Margalit, 1977).

Ullmann-Margalit (1977) desenvolveu um estudo em que se propôs a realizar a reconstrução racional das características formais dos estados de interação social através dos quais as normas são geradas, interessando-se pelos tipos de normas e a maneira como são geradas, não no sentido histórico, mas estrutural. Contextos de interação social implicam situações em que os participantes reconheçam a interdependência de expectativas, decisões e ações, diferindo da teoria do processo decisório que considera o tomador de decisão isolado, em condições arriscadas e incertas. Por interação social entende-se:

a number of persons who cannot behave as if the actions of the others were given and hence still make their decisions in isolation; rather, these persons are interacting in an essential way, such that no choice of action can be made wisely without taking into account the dependence of the outcome on the participants' mutual expectations (Ullmann-Margalit, 1977, p. 7).
A autora procurou então estudar as condições que fazem emergir as normas através de algumas interações paradigmáticas com o auxílio da teoria dos jogos, acreditando ser possível desenvolver uma descrição abstrata e relativa das normas daí resultantes. O argumento básico é que as normas surgem como soluções para problemas postos por determinadas situações de interação social.

A correlação entre certos tipos de situaçõesproblema e as normas que facilitam a sua solução é a justificativa para a geração dessas mesmas normas. Desta maneira, normas representam um papel funcional e podem não atender necessariamente aos interesses de todas as partes ou da sociedade como um todo. A solução para um problema é o tipo de conexão específica entre as normas e as interações paradigmáticas, o que justifica a sua geração mais do que um mecanismo projetado para criá-las. Melhor dizendo, algumas referências desse tipo podem até ser encontradas para as normas das situações de coordenação, mas elas são consideradas de maneira secundária, pois precisarão ser legitimadas pelos membros (Ullmann-Margalit, 1977).

Ainda que enfoquem objetos diferentes, encontramos nas teses de Tuomela (2000) e UllmannMargalit (1977), sobre a cooperação e a emergência das normas, respectivamente, um ponto comum: ambas resultam de interações sociais, a cooperação como reconhecimento de algum grau de dependência, as normas como soluções para problemas.

Tais estudos nos induzem a concluir que a organização do trabalho capitalista, típica da empresa tradicional, gera uma estrutura e uma dinâmica que, sim, dependem da cooperação, mas uma cooperação de tipo I-cooperation definida e legitimada de antemão pela racionalidade organizacional vigente (funcional/burocrática), para realizar objetivos projetados por uma pessoa ou grupo através do trabalho coordenado de outros indivíduos, ainda que, analisando as teses de Tuomela e como as normas emergem das interações sociais, a realização de uma cooperação sofisticada até mesmo em uma empresa tradicional não seria impossível - como no caso de uma organização mais orgânica, participativa e descentralizada. Já as empresas autogestionárias, em sua maioria, têm um diferencial: surgem da cooperação e associação voluntária, não em função do investimento de capital e do direito de propriedade.

De fato, mais recentemente, o francês Christophe Dejours - um dos responsáveis pelo surgimento da psicodinâmica do trabalho - defendeu essa ideia, porém, seguindo outra linha. Esse autor desenvolveu uma definição crítica para o trabalho evocando a dimensão da cooperação, pensando o que é necessário para se constituir uma equipe ou um coletivo unido para trabalhar junto (Dejours, 2012). O objetivo do autor foi desenvolver a ideia 
do poder emancipatório que o trabalho pode ter, já que tal ideia foi objeto de embates entre marxistas, dos quais foi retida principalmente a ideia de que o trabalho aliena. Outros aproveitaram a ideia de que através das provações do trabalho os poderes do ser humano poderiam ser revelados para ele mesmo, bem como a ideia de que o trabalho social era o caminho para a emancipação.

O trabalho coletivo é o elo entre a inteligência, a habilidade e a engenhosidade existentes potencialmente em cada indivíduo e a forma como pode contribuir à cultura ou à polis, sendo a mobilização das inteligências individuais. Trabalho prescrito concretiza-se pela coordenação, já o trabalho coletivo só pode ocorrer por meio da cooperação. Esse trabalho pode ser orientado por um objetivo instrumental - conseguir produzir alguma coisa juntos -, mas o que une é a vontade de realizar uma obra comum que mobilize as relações entre os indivíduos. O trabalho enquanto atividade coletiva através da cooperação é visto então como via de emancipação para o indivíduo, possibilitando contrabalançar as tendências mais egoísticas por conta da experiência coletiva de construir uma obra comum (Dejours, 2012).

A cooperação não é uma construção espontânea, mas uma prática complexa e permeada de contradições. $O$ espaço de deliberação interno na organização só existe se a direção da empresa concede este espaço de discussão e poder para os seus trabalhadores. Dejours (2012) argumenta que pode haver emancipação pelo trabalho através da cooperação, como atividade construída por um coletivo, até mesmo no âmbito da empresa tradicional, desde que a administração conceda espaço para isto. Não obstante, vemos que essa possibilidade carrega contradições próprias da propriedade e das relações de poder que lhes são inerentes: em um contexto de necessidade, o funcionário continua sendo variável de ajuste. No âmbito de empresas autogestionárias, a propriedade é coletiva e o espaço de construção é criado pelos próprios trabalhadores; sendo uma experiência política, é possível que se desenvolva uma dinâmica de cooperação mais próxima ou, de fato, realizável nos termos da g-cooperation descrita por Tuomela (2000), de tal modo que os cooperativistas desenvolveram os princípios cooperativos (como normativas), a recordação dos valores e normas que regem esse tipo de organização.

Este seria então um modelo de organização que gera condições mais favoráveis para a cooperação, seja entre os membros internamente - por mais que os benefícios da cooperação em si não tenham sido o foco inicial de interesse, uma vez que as pessoas normalmente se articulam para suprir necessidades econômicas ou de sobrevivência -, seja entre a cooperativa e o seu ambiente externo - quando a cooperação extrapola o ambiente interno da cooperativa, que passa a cooperar também com outras entidades do seu ambiente, agindo no seu espaço (Barros \& Oliveira, 2019; Comissario \& Webering, 2017; Webering, 2019).

As estruturas sociais, como se desenvolveram no último século, contribuíram com uma espécie de normatização do comportamento utilitarista entre os indivíduos; a cooperação, quando existe, também se dá em termos individualistas e não no sentido de como as ações de cada um repercutem na vida do outro ou no coletivo. Ainda assim, devido à sua própria autonomia, o homem é capaz de encontrar formas alternativas para a sua autorrealização, o que explica o surgimento dessas organizações, seja como mecanismo de sobrevivência, seja como uma alternativa consciente de organização do trabalho.

\section{CONSIDERAÇÕES FINAIS}

A maneira como foi concebida a pesquisa aqui sintetizada percorreu um caminho elucidativo na compreensão do fenômeno da cooperação e do empreendimento cooperativo, superando a análise conjuntista "do que é feito?" (Le Moigne, 1996, p. 31), respondendo à pergunta "o que faz?" (Le Moigne, 1996, p. 31). A triangulação proposta por Le Moigne (1996) foi preenchida com elementos que nos ajudam a compreender a história dessas experiências, razões para seu surgimento e desenvolvimento (o ser), a prática e o que acontece quando em contato com o ambiente (o fazer) e, finalmente, as tendências evolutivas ou os caminhos possíveis que podem percorrer (o devir). Foi aprofundado o organizacionismo tendo em mente que essa é uma perspectiva autorreflexiva e, portanto, sempre incompleta (Morin, 2007).

O desafio assumido neste trabalho foi o esforço de reconstrução do conhecimento sobre a cooperação, especialmente a que inspira a autogestão de empreendimentos econômicos, retomando teorias e conceitos já clássicos, como essas experiências foram vistas no âmbito do próprio cooperativismo, e como foram complementadas com pesquisas mais recentes ligadas à teoria dos jogos (Axelrod, 2010) e à filosofia analítica para o estudo da cooperação (Tuomela, 2000). Portanto, a maneira pela qual foi desenvolvido procurou resolver o problema do complexo, sem negar que esse tipo de empreendimento sofre grandes desafios, dificuldades muitas vezes insuperáveis. Cooperativas representam projetos políticos e nesse universo existem claras diferenças.

Para atingir seus objetivos sociais e econômicos, cooperativas precisam combinar a perspectiva de reprodução interna dos membros e enfrentar pressões ambientais, sendo que elas evoluem com mais qualidade quanto mais possuírem autonomia e 
forem orientadas pelos membros, para os membros. Neste sentido, a degeneração não é inevitável (Stryjan, 1994; Manoa, 2001; Cornforth, 1995).

O quadro institucional mais amplo da sociedade está fundamentado no modelo organizacional burocrático e de mercado. Para que haja uma expansão dos empreendimentos cooperativos, essa discussão perpassa, sem dúvidas, o fortalecimento do quadro institucional cooperativo para que se desenvolvam fontes isomórficas congruentes deste modelo.

Cooperativas transformam a dinâmica da organização do trabalho capitalista, em que os trabalhadores não se articulam por vontade própria, mas têm seu trabalho coordenado por terceiros, pois são formadas com base na cooperação entre os próprios trabalhadores. Porém, como organizações humanas também passam por um processo evolutivo, sofrendo os problemas próprios da administração e manutenção da democracia, do surgimento de uma classe dirigente, da divisão do trabalho e de

\section{REFERÊNCIAS}

Arvon, H. (1985). L' autogestión. Paris: Presses Universitaires de France.

Axelrod, R. (2010). A evolução da cooperação. São Paulo: Leopardo Editora.

Axelrod, R. (1984). The Evolution of Cooperation. New York: Basic Books.

Bager, T. (1994). Isomorphic processes and the transformation of cooperatives. Annals of Public and Cooperative Economics, 65(1), 35-39. https://doi. org/10.1111/j.1467-8292.1994.tb01401.x

Barros, V. A. de, \& Oliveira, F. G. de. (2019). Cooperação e solidariedade em empreendimentos de economia solidária. Laboreal, 15(1), 1-22. http://dx.doi. org/10.4000/laboreal.986

Bear, A, \& Rand, D. G. (2016). Intuition, deliberation, and the evolution of cooperation. PNAS - Proceedings of the National Academy of Sciences of The United States of America, 113(4), 936-941. https://doi.org/10.1073/ pnas. 1517780113

Bialoskorski, S. N. (2004). Gobierno y papel de los cuadros directivos en las cooperativas brasileñas: Estudio comparativo. CIRIEC - España, Revista de Economía Pública Social y Cooperativa, (48), 225-241. Retrieved from http://ciriec-revistaeconomia.es/wp-content/ uploads/10_Bialoskorski_48.pdf

Baum, J. A. C. (2007). Ecologia organizacional. In S. Clegg (Org). Handbook de estudos organizacionais. Modelos de análise e novas questões em estudos organizacionais (Vol.1, pp.135-193). São Paulo: Atlas. disputas de poder. Contudo, conhecer e entender esses dinamismos é parte importante para o desenvolvimento de estratégias autorreforçantes da identidade cooperativa.

O trabalho construído coletivamente, mesmo sendo realizado para garantir a sobrevivência do indivíduo, através da cooperação ganha novos sentidos, pois recupera sua autonomia e o potencial emancipador do trabalho coletivo, gerando melhores condições para o equilíbrio entre a racionalidade substancial e a racionalidade funcional (Desroche, 2006).

Espera-se com isso contribuir com a urgência de se repensar o trabalho e as relações que ele emana: uma humanidade e liberdade repensadas. Ao contrário do que se disseminou, não somos apenas competitivos, somos também cooperativos e nosso conhecimento precisa ser urgentemente reconstruído.

Bauman, Z. (2004). Amor Líquido. Rio de Janeiro: Jorge Zahar Ed.

Bowles, S., \& Gintis, H. (2011). A cooperative species: Human reciprocity and its evolution. New Jersey: Princeton University Press.

Bretos, I., \& Errasti, A. (2016). Challanges and opportunities for the regeneration of multinational worker cooperatives: Lessons from the Mondragon Corporation - a case study of the Fagor Ederlan Group. Organization, 24(2), 154173. https://doi.org/10.1177/1350508416656788

Bretos, I., \& Errasti, A. (2018). The challenges of managing across borders in worker cooperatives: Insights from the Mondragon cooperative group. Journal of $\mathrm{Co}$ operative Organization and Management, 6(1), 34-42. https://doi.org/10.1016/j.jcom.2018.04.001

Candau, J. (2018). Coopération, Anthropen.org. Paris: Éditions des archives contemporaines. https://doi. org/10.17184/eac.anthropen.074

Chaves, R. (1999). La Economía social como enfoque metodológico, como objeto de estudio y disciplina científica. CIRIEC - España, Revista de Economía Pública Social y Cooperativa, (33), 115-139. Retrieved from: http://ciriec-revistaeconomia.es/wp-content/ uploads/05_Chaves_33.pdf

Chaves, R., \& Sajardo, A. (2004) Economía política de los directivos de las empresas de economía social. CIRIEC - España, Revista de Economía Pública Social y Cooperativa, (48), 31-52. Retrieved from: http:// ciriec-revistaeconomia.es/wp-content/uploads/02_ Chaves_y_Sajardo_48.pdf 
Cheney, G., Cruz, I. S., Peredo, A. M., \& Nazareno, E. (2014). Worker cooperative as an organizational alternative: Challenges, achievements and promise in business governance and ownership. Organization, 21(5), 591603. https://doi.org/10.1177/1350508414539784

Comissario, G., \& Webering, S. I. (2017, dezembro). Sentidos do trabalho: Uma perspectiva de trabalhadores de Economia Solidária. Anais da Conferência Internacional de Pesquisa sobre Economia Social e Solidária - CIRIEC. Recife, PE, Brasil, 6.

Cornforth, C. (1995). Patterns of cooperative management: Beyond the degeneration thesis. Economic and Industrial Democracy, 16(4), 487-523. https://doi. org/10.1177/0143831X95164002

Dejours, C. (2012). Trabalho vivo: Trabalho e emancipação (Vol. 2). Brasília: Paralelo 15.

Denzin, N., \& Lincoln, Y. (2006). A Disciplina e a prática da pesquisa qualitativa. In N. Denzin, \& Y. Lincoln (Eds). $O$ planejamento da pesquisa qualitativa: Teorias $e$ abordagens. (pp. 15-41). Porto Alegre: Artmed.

Desroche, H. (1976). Le projet coopératif. Paris: Éditions Économie et Humanisme; Éditions Ouvrières.

Desroche, H. (2006). Sobre o projeto cooperativo: Democracia, emancipação, ética. In M. Thiollent (Ed.). Pesquisaação e projeto cooperativo na perspectiva de Henri Desroche. (pp. 131-154). São Carlos: Editora UFSCar.

Dimaggio, P. J., \& Powell, W. (2005). A gaiola de ferro revisitada: Isomorfismo institucional e racionalidade coletiva nos campos organizacionais. RAE: Revista de Administração de Empresas, 45(2), 74-89. Retrieved from: https://rae. fgv.br/sites/rae.fgv.br/files/gaiola-ferro-revisitadaisomorfismo-institucional-racionalidade-coletiva-noscampos-organizacionais_0.pdf

Errasti, A. (2013). Mondragon's chinese subsidiaries: Coopitalist multinationals in practice. Economic and Industrial Democracy, 36(3). 479-499. https://doi. org/10.1177/0143831X13511503

Fauquet, G. (1980). O sector cooperativo. Lisboa: Livros Horizonte.

Fiani, R. (2006). Teoria dos jogos: Com aplicações em Economia, Administração e Ciências Sociais. Rio de Janeiro: Campus; Elsevier.

Gambetta, D. (1996). Confiança e cooperação. In W. Outhwaite, T. Bottomore, (Eds.), Dicionário do pensamento social do século $X X$ (pp.119-120). Rio de Janeiro: Jorge Zahar Editor.

Grossmann, I., Brienza, J. P., \& Bobocel, D. R. (2017). Wise deliberation sustains cooperation. Nature Human Behaviour, 1(0061). http://doi.org/10.1038/s41562017-0061

Hannan, M. T., \& Freeman, J. (2005). Ecologia populacional das organizações. RAE: Revista de Administração de Empresas, 45(3). Retrieved from: https://rae. fgv.br/sites/rae.fgv.br/files/ecologia-populacionalorganizacoes_0.pdf

Kropotkin, P. (1902). Mutual aid: A factor of Evolution. London: Heinemann, 1902.
Jesus, P., \& Tiriba, L. Cooperação (2003). In A. Cattani. (Ed.) A outra Economia. (pp. 49-54). Porto Alegre: Veraz.

Lasserre, G. (1972). El cooperativismo. Barcelona: Oikos-Tau Ediciones.

Le Moigne, J. (1996). A teoria do sistema geral. Lisbon: Instituto Piaget.

Manoa, J. (2001) Structure de groupe et économie sociale. In D. Côté. (Ed.) Les holdings coopératifs: Evolution ou transformation définitive? (pp. 23-52). Brussels: De Boeck \& Larcier.

Martínez, J. (2005). ¿Cómo seguir compartiendo soluciones? La gestión del ciclo de vida cooperativo. Cayapa: Revista Venezolana de Economía Social, 5(9), 4-22. Retrieved from: http://www.saber.ula.ve/ bitstream/handle/123456789/18688/articulol. pdf? sequence $=2 \&$ isAllowed $=y$

Marx, K. (2002). O capital: Crítica da Economia Política. Livro Primeiro (Vol. 1). Rio de Janeiro: Civilização Brasileira.

Maturana, H., \& Varela, F. (1997). De máquinas e seres vivos: Autopoiese, a organização do vivo. Porto Alegre: Artes Médicas.

Meister, A. (1969). Los sistemas cooperativos: Democracia o tecnocracia? Barcelona: Editorial Nova Terra.

Meister, A. (1972). Vers une sociologíe des associations. Paris: Éditions Économie et Humanisme; Éditions Ouvrières.

Michels, R. (1969) Los partidos políticos: Un estudio sociológico de las tendencias oligárquicas de la democracia moderna (Vol. 2). Buenos Aires: Amorrortu Editores.

Morin, E. (2007). Introdução ao pensamento complexo. Porto Alegre: Sulina.

Mozas Moral, A. (2004). La violación del modelo de gestión democrático en las cooperativas oleícolas. CIRIEC - España, Revista de Economía Pública Social y Cooperativa, (48), 167-191. Retrieved from: http:// ciriec-revistaeconomia.es/wp-content/uploads/08_ Mozas_48.pdf

Spear, R. (2004). El Gobierno democrático en las organizaciones cooperativas. CIRIEC - España, Revista de Economía Pública Social y Cooperativa, (48), 11-30. Retrieved from: http://ciriec-revistaeconomia.es/wp-content/ uploads/01_Spear_48.pdf

Stryjan, Y. (1994). Understanding cooperatives: The reproduction perspective. Annals of Public and Cooperative Economics, 65(1), 59-79. https://doi. org/10.1111/j.1467-8292.1994.tb01506.x

Tuomela, R. (2000). Cooperation. Philosophical studies series. Dordrecht; Boston; London: Kluwer Academic Publishers.

Ullmann-Margalit, E. (1977). The emergence of norms. Clarendon Library of Logic and Philosophy. Oxford: University Press.

Weber, M. (2009). Economia e sociedade. (Vol. 1). Brasília: Editora Universidade de Brasília.

Webering, S. I. (2019). Economia social, non-profit sector, terceiro setor ou economia solidária: Sentidos, diferenças e similaridades. P2P e Inovação, 5(2), 62-82. 


\section{Autoria}

\section{Susana Iglesias Webering*}

Av. Governador Roberto Silveira, s/n, Moquetá, 26285-060, Nova Iguaçu, RJ, Brasil.

E-mail: suiwebering@gmail.com

(1) https://orcid.org/0000-0002-7832-8183

* Autora Correspondente

\section{Contribuições dos Autores}

$1^{\text {a }}$ autora: administração do projeto (igual), conceitualização (líder), metodologia (líder), redação - rascunho original (líder) e redação - revisão e edição (líder).

\section{Nota}

Uma versão preliminar desse artigo foi apresentada no $\mathrm{X}$ Encontro de Estudos Organizacionais da ANPAD (ENEO 2019).

\section{Financiamento}

Os autores informaram que não houve apoio financeiro para a pesquisa neste artigo.

\section{Conflito de Interesses}

Os autores informaram que não há conflito de interesses.

\section{Direitos Autorais}

A RAC detém os direitos autorais deste conteúdo.

\section{Verificação de Plágio}

A RAC mantém a prática de submeter todos os documentos aprovados para publicação à verificação de plágio, mediante o emprego de ferramentas específicas, e.g.: iThenticate..

\section{Método de Revisão por Pares}

Este conteúdo foi avaliado utilizando o processo de revisão por pares duplo-cego (double-blind peer-review). A divulgação das informações dos pareceristas constantes na primeira página é feita somente após a conclusão do processo avaliativo, e com o consentimento voluntário dos respectivos pareceristas. 